bioRxiv preprint doi: https://doi org/10.1101/2020 10.08.331116; this version posted May 17, 2021. The copyright holder for this preprint (which was not certified by peer review) is the author/funder, who has granted bioRxiv a license to display the preprint in perpetuity. It is made available under aCC-BY-NC-ND 4.0 International license.

\title{
Effects of High Magnetic Fields on Diffusion of Biologically Active Molecules
}

\author{
Vitalii Zablotskii ${ }^{1,2 *}$, Tatyana Polyakova ${ }^{1}$, and Alexandr Dejneka ${ }^{1}$ \\ ${ }^{1}$ Department of Optical and Biophysical Systems, Institute of Physics of the Czech Academy of Sciences, \\ Prague, 18221, Czech Republic \\ ${ }^{2}$ International Magnetobiology Frontier Research Center (iMFRC), Science Island, 230031, China
}

*Corresponding author: email zablot@fzu.cz

Keywords: Interaction between magnetic field and cell; Molecular diffusion; Intracellular ROS; Gas exchange in RBC; Hemoglobin; Drug diffusion

\begin{abstract}
The diffusion of biologically active molecules is a ubiquitous process, controlling many mechanisms and the characteristic time scales for pivotal processes in living cells. Here, we show how a high static magnetic field (MF) affects the diffusion of paramagnetic and diamagnetic species, including oxygen, hemoglobin, ROS and drugs. We derive and solve the equation describing diffusion of such biologically active molecules in the presence of a MF as well as reveal the underlying mechanism of the MF effect on diffusion. We find that a high MF accelerates diffusion of diamagnetic species while slowing the diffusion of paramagnetic molecules in cell cytoplasm. When applied to oxygen and hemoglobin diffusion in red blood cells, our results suggest that a MF may significantly alter the gas exchange in an erythrocyte and cause swelling. Our prediction that the diffusion rate and characteristic time can be controlled by a MF opens new avenues for experimental studies foreseeing numerous biomedical applications.
\end{abstract}


bioRxiv preprint doi: https://doi.org/10.1101/2020.10.08.331116; this version posted May 17, 2021. The copyright holder for this preprint

\section{Introduction}

While humans, animals and plants have always been exposed to natural magnetic fields (MFs), the increasing number of applications of strong MFs and their impact on living beings and the environment are presenting more questions than answers. Currently, numerous experimental techniques allow the generation of magnetic fields in the range of thousands of teslas. The world's strongest resistive 41.4-45 tesla magnet capable of running continuously were engineered in the National High Magnetic Field Laboratory at Florida State University (2017) and the High Magnetic Field Laboratory Hefei Institutes of Physical Science, Hefei, China. Static magnetic fields with a magnetic induction 17.6-21 T are used in MRI instruments for better image resolution and more accurate diagnosis [1,2]. In pulsed regimes, peak fields of $1200 \mathrm{~T}$ were generated with newly developed magnetic systems $[3-5]$.

Diffusion is one of the most pervasive processes that controls many mechanisms in cell machinery. Diffusion rate governs the characteristic time scale for intracellular processes, which play pivotal roles in many cell functions, such as regulation of cell membrane potential, cell motility, division, gas exchange, intracellular transport and cell signaling. Thus, since diffusion is often the dynamic basis for a broad spectrum of different intracellular processes, cell functions could be modified by a proper tuning of the diffusion rate of some diffusing species, e.g., tuning of the diffusion coefficient with a magnetic field.

The effects of magnetic field on diffusion has been a topic of investigation since early observations of the effects of static uniform and nonuniform magnetic fields of diffusion on paramagnetic species [6,7]. Interactions between a magnetic field and living cells may result in the appearance of a variety of biomagnetic effects at the cellular and organism levels [8-15]. Many intriguing mechanisms have been suggested to explain biomagnetic effects [1621]. The biological effects of high and ultrahigh magnetic fields are of particular interest, for example: $9.4 \mathrm{~T}$ static MF suppress lung cancer growth [15]; 10.5 T MRI static MF effects on human cognitive, vestibular, and physiological function [22]; $16.4 \mathrm{~T}$ static MF results in long-term impairment of the vestibular system in mice [23]; 27 T static MF changes orientation and morphology of mitotic spindles in human cells [24]. An important but poorly understood factor that may affect intracellular processes and chemical reactions is the role of magnetic fields in the diffusion of biologically active molecules. In this work, we propose the mechanisms of the magnetic control of diffusion and discuss biological consequences related to the diffusion of some biologically active molecules in static uniform magnetic fields. 
bioRxiv preprint doi: https://doi. org/10.1101/2020.10.08.331116; this version posted May 17, 2021. The copyright holder for this preprint (which was not certified by peer review) is the author/funder, who has granted bioRxiv a license to display the preprint in perpetuity. It is made available under aCC-BY-NC-ND 4.0 International license.

Let us start with a brief description of the relevant magnetic forces that may affect diffusion in cells. When a static magnetic field (MF) is applied to cell systems, three types of magnetic forces can act on subcellular components, molecules and ions: i) the Lorentz force, $\boldsymbol{F}_{\boldsymbol{L}}=q[\boldsymbol{v B}]$ (where $\boldsymbol{B}$ is the magnetic induction, $q$ is the ion electric charge and $v$ is its velocity); ii) the magnetic gradient force, $F_{\nabla_{B}} \propto \nabla B^{2}$ [25-27] (when the magnetic field is uniform ( $\nabla B \approx 0$ ), the magnetic gradient force is negligible); and iii) the concentration-gradient magnetic force, $F_{\nabla_{n}} \propto B^{2} \nabla n$ [28-30] (where $\nabla n$ is the gradient of the concentration of diamagnetic and paramagnetic species and $\nabla$ is the differential operator nabla).

The concentration-gradient magnetic force will be considered as the main driving force in our model describing the MF effect on diffusion in cells. In fact, living cells are far from thermodynamic equilibrium, and hundreds of diamagnetic and paramagnetic species inside cells may have very large concentration gradients [31]. Thus, in the presence of a high MF, a relatively large concentration-gradient magnetic force can be operative in cells. In cells, this force can redistribute paramagnetic free radicals, such as $\mathrm{O}_{3}, \mathrm{NO}$, and $\mathrm{NO}_{2}$ and the molecules $\mathrm{FeCl}_{3}$ and $\mathrm{O}_{2}$, thereby altering the cell machinery and changing cell fate. However, the effects of a MF on the intracellular reactive oxygen species (ROS) level and ROS trafficking are still perplexing, for a review see work [32].

Here, we demonstrate how the concentration-gradient magnetic force can drive diffusion of paramagnetic and diamagnetic species in cells. We show that even though the concentration-gradient magnetic forces exerted on diffusing molecules are small, they may play an important role in the presence of sufficiently high magnetic fields.

The remainder of the paper is organized as follows. In Section 2.1 we provide the basic formulas for the concentration-gradient magnetic force. In Section 2.2, using calculations of the species concentration as a function of both coordinate and time, we show that a high MF can change the characteristic time of diffusion: accelerating diffusion of diamagnetic molecules and ceasing diffusion of paramagnetic molecules. In Section 2.3, we analyze the role of the magnetic concentration-gradient force in the diffusion of hemoglobin and oxygen in red blood cells (RBC) as well as the diffusion of some biologically active molecules and ROS. The achieved results and prospects for further research are discussed in Section 3. 


\section{Results}

\subsection{Magnetic concentration-gradient force}

Let us consider a case when a uniform static magnetic field $(\nabla B=0)$ is applied to a cell. In this case, the magnetic concentration- gradient force, $F_{\nabla_{n}}$ acts on diamagnetic and paramagnetic ions and can either assist or oppose ion movement through the cell. The volume density of the concentration-gradient magnetic force is given by [25]:

$$
\vec{f}=\frac{\chi B^{2}}{2 \mu_{0}} \vec{\nabla} n
$$

where $n$ is the molar concentration of ions with the molar magnetic susceptibility $\chi$ and $\mu_{0}$ is the vacuum permeability. In a particular case when the concentration only depends on one coordinate, $x$, the force is determined as follows:

$$
f(x)=\frac{\chi B^{2}}{2 \mu_{0}} \frac{d n(x)}{d x}
$$

To analyze the influence of this magnetic force on the diffusion of paramagnetic or diamagnetic molecules we calculate the force exerted per a molecule, $f_{l}=f /\left(n N_{A}\right)$. From Eq. 1, this force reads as:

$$
\vec{f}_{1}=\frac{\chi B^{2}}{2 \mu_{0} n N_{A}} \vec{\nabla} n
$$

Under this force (Eq. 3), a molecule moves with the velocity $\boldsymbol{u}=\not \boldsymbol{f}_{1}$, where $\gamma$ is the mobility of a diffusing molecule in a solution. Depending on the sign of the magnetic susceptibility $(\chi<0$ for diamagnetic, and $\chi>0$ for paramagnetic species), the force is either parallel or antiparallel to the concentration gradient. Thus, the magnetic field directly affects diffusion by orienting the diffusion velocity. Several effects related to the role of the force (Eq.3) in diffusion are considered in detail below. 


\subsection{Magnetic field effect on diffusion of paramagnetic and diamagnetic molecules}

The differential equation that describes the diffusion of molecules in a solution moving with velocity $u$ is described as [25,33-35]

$$
\frac{\partial n}{\partial t}=D \nabla^{2} n-(\vec{\nabla} \cdot n \vec{u})
$$

where $D$ is the diffusion coefficient. Substantiating $\boldsymbol{u}=\not \boldsymbol{f}_{l}$ into Eq.3, one can arrive at

$$
\frac{\partial n}{\partial t}=D_{e f f} \nabla^{2} n
$$

where $D_{\text {eff }}=\left(D-\frac{\gamma \chi B^{2}}{2 \mu_{0} N_{A}}\right)$ is the effective diffusion coefficient. Given that the mobility $(\gamma)$ of the diffusing molecule in a solution may be calculated using the Nernst-Einstein relation $\gamma=D / k_{B} T$ (where $k_{B}$ is the Boltzmann constant and $T$ is the temperature), one can arrive at

$$
D_{e f f}(B)=D(1-\beta)
$$

where

$$
\beta=\frac{\chi B^{2}}{2 \mu_{0} R T}
$$

and $R=8.31 \mathrm{~J} /(\mathrm{K} \mathrm{mol})$ is the gas constant.

Thus, the diffusion process affected by the concentration-gradient magnetic force is described by Eq.5 with $D_{\text {eff }}(B)$, which is a partial differential equation. As seen from Eqs. 6(a,b), a MF decreases $(\beta>0)$ the diffusion coefficient for paramagnetic molecules $(\chi>0)$ and increases it $(\beta<0)$ for diamagnetic molecules $(\chi<0)$. The case $\beta<<1$ describes the effects of weak magnetic fields on diffusion. The parameter, $\beta \approx 1$ corresponds to the suppression of the diffusion of paramagnetic molecules when the concentration flux (Fick's law) and magnetic flux compensate each other. 
bioRxiv preprint doi: https://doi.org/10.1101/2020 10.08.331116; this version posted May 17, 2021. The copyright holder for this preprint (which was not certified by peer review) is the author/funder, who has granted bioRxiv a license to display the preprint in perpetuity. It is made available under aCC-BY-NC-ND 4.0 International license.

The mechanism of the suppression of the diffusion process is qualitatively explained as follows. In a diffusion process, particle flux due to the gradient in concentration is directed from the highest concentration to the lowest concentration, $J_{D}=-D d n / d x$ (Fick's law), which is antiparallel to $\nabla n$. Note, this flux is driven by the second law of thermodynamics.

In the presence of magnetic fields, a magnetically driven flux $\left(J_{m a g}\right)$ arises to decrease the magnetic energy of the system (which is negative with the volume density $-c(\boldsymbol{p B})$, where $\boldsymbol{p}$ is the vector of the particle's magnetic moment and $c$ is the volume concentration of paramagnetic solute) and tends to move paramagnetic molecules towards an area with highest particle concentration. Indeed, the magnetic concentration-gradient force is parallel to $\nabla \mathrm{n}$ as noted in Eq. 1. Thus, the magnetic flux $\left(j_{m a g}\right)$ is driven by the energy minimization and is parallel to $\nabla n$ (Figure 1a). Since the $J_{D}$ and $J_{m a g}$ fluxes are antiparallel, the diffusion rate is decreased (for illustration see Figure 1a).

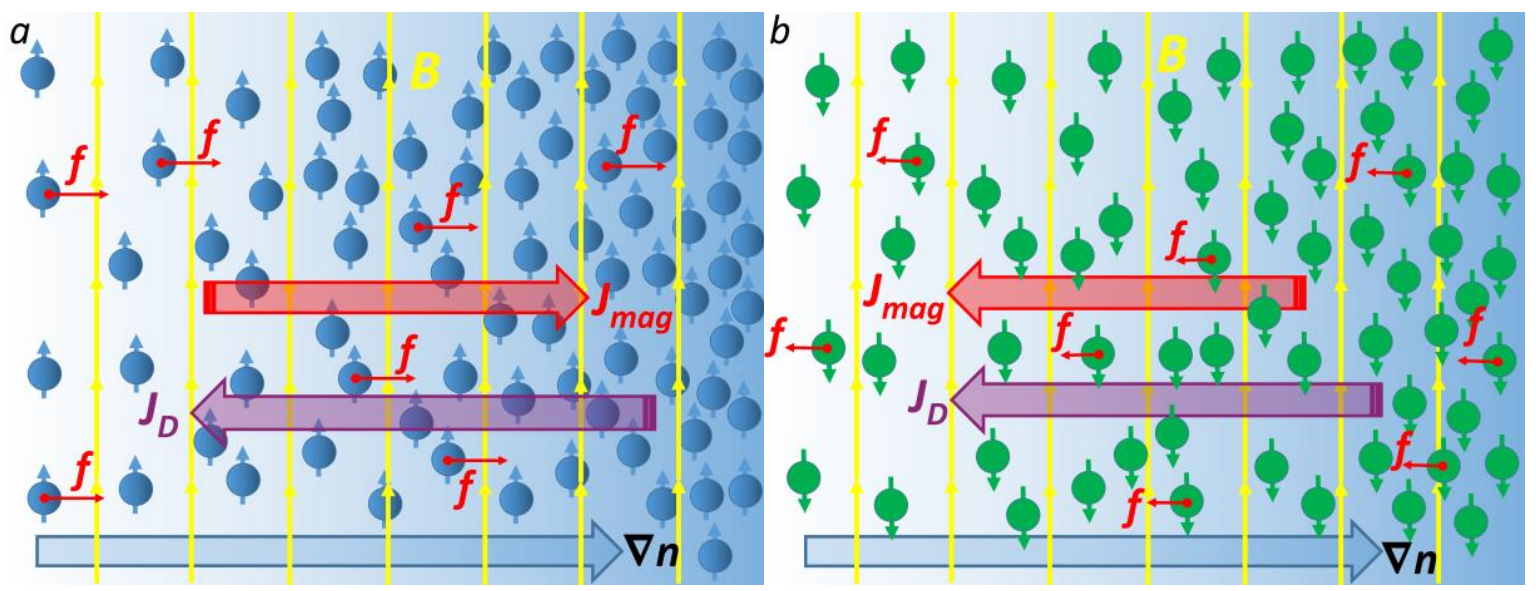

Figure 1. Sketch of magnetically affected diffusion of paramagnetic $(a)$ and diamagnetic molecules $(b)$. The yellow arrows represent the magnetic field lines. The large blue arrow shows the concentration gradient $\nabla \mathrm{n}$ of solute. Red arrows show magnetic concentration-gradient forces (Eq. 1) acting on molecules.

In the case of diamagnetic solute $(\chi<0)$ the magnetic force (Eq. 1) is antiparallel to the concentration gradient, and therefore, the $J_{D}$ and $J_{m a g}$ fluxes are parallel (Figure 1b). This finding implies that a magnetic field accelerates the diffusion of diamagnetic molecules. However, since diamagnetic susceptibilities are several orders of magnitude less than paramagnetic susceptibilities, the magnetic effect on diffusion is rather small. However, $\operatorname{since} \beta \propto T^{-1}$ (Eq. 6b), the magnetic contribution to the diffusion increases as the temperature decreases. Thus, at low temperatures, one can expect a noticeable effect of high magnetic fields on the diffusion rate of diamagnetic species. 
bioRxiv preprint doi: https://doi org/10.1101/2020 10.08.331116; this version posted May 17, 2021. The copyright holder for this preprint (which was not certified by peer review) is the author/funder, who has granted bioRxiv a license to display the preprint in perpetuity. It is made available under aCC-BY-NC-ND 4.0 International license.

A 3D diffusion problem with spherical symmetry is described by the following equation:

$$
\frac{\partial n}{\partial t}=D_{e f f}(B)\left(\frac{\partial^{2} n}{\partial r^{2}}+\frac{2}{r} \frac{\partial n}{\partial r}\right)
$$

where $r$ is the radial coordinate.

To solve the differential Eq. 7, we chose simplest boundary and initial conditions:

$$
\mathrm{n}(t, 0)=0, n(t, R)=n_{0} \text { and } n(0, r)=g(r)
$$

where $n_{0}$ is the constant concentration at the surface of the sphere, $r=R$ and the function $g(r)$ is the initial concentration inside the sphere. Our choice of boundary conditions is determined by biologically relevant diffusion problems in cells and tissues. For example, the differential equation describing the ATP diffusion between a source and sinks was solved under the boundary conditions fixing the ATP concentrations at two spatially separated planes in work [31]. Boundary conditions of this type are applicable in cell biophysics to solve the following problems: diffusion through a cell membrane, lateral diffusion of proteins in membranes, intracellular signaling and calcium dynamics, drug diffusion through tissue, diffusion of transcription factors and other DNA-binding proteins along DNA, and gas diffusion in erythrocytes. Below we apply Eq.7 with the imposed boundary conditions (Eq.8), to the analysis of the diffusion of hemoglobin and oxygen in red blood cells as well as the diffusion of ROS.

The solution of the Eqs. 7 and 8 is described by the equation [36]

$$
n(t, r)=n_{0}\left(1+\frac{2 R}{\pi R} \sum_{n=1}^{\infty} \frac{(-1)^{n}}{n} \operatorname{Sin}\left(\frac{n \pi r}{R}\right) \operatorname{Exp}\left[-\frac{D(1-\beta) \pi^{2} n^{2}}{R^{2}} t\right]\right)
$$

In Figure 2 (a-c), we show the solution of Eq. 9 as the density plots of $n(t, r) / n_{0}$, calculated using Wolfram Mathematica 10 software [37], for the three cases: diffusion with no magnetic field $(\beta=0)$ and diffusion in a magnetic field $(\beta=0.5$ and $\beta=-0.5)$. The calculations of $n(t, r) / n_{0}$ were performed for $R=5 \mu \mathrm{m}, D=10^{-9} \mathrm{~m}^{2} / \mathrm{s}$ which is the $\mathrm{O}_{2}$ diffusivity inside a red blood cell ( $\left.\mathrm{RBC}\right)[38]$. 

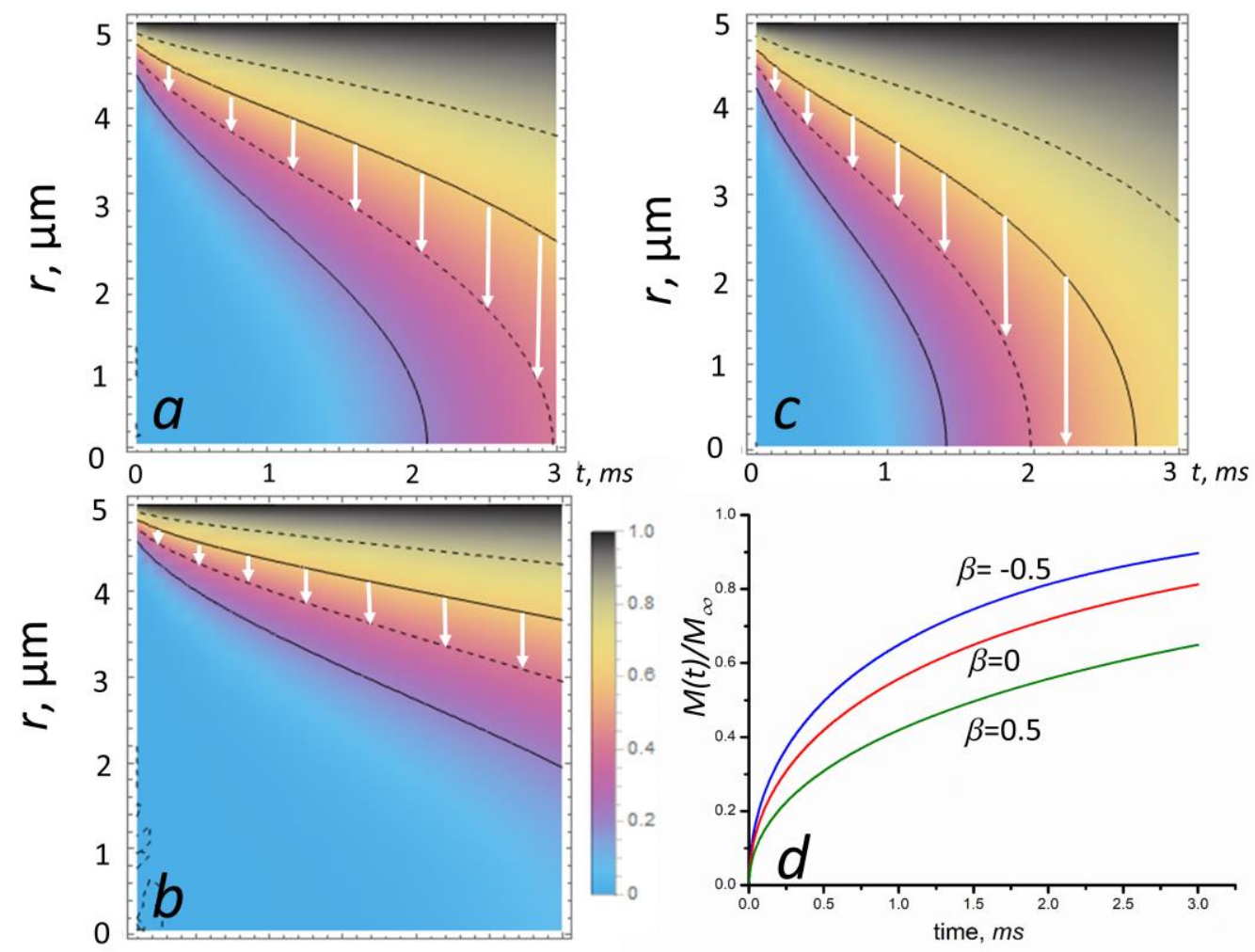

Figure. 2. MF effect on diffusion in a sphere: the contour plots of $n(t, r) / n_{0}$ given by Eq. 9 . The sphere is initially at a uniform zero concentration and the surface concentration is maintained constant at $n_{o}$. The curves represent $\left.n(t, r) / n_{0}: a\right)$ with no magnetic field $\left.(\beta=0), b\right)$ with a magnetic field corresponding $\beta=0.5$ (paramagnetic species) and $c$ ) with a magnetic field corresponding $\beta=-0.5$ (diamagnetic species). The calculations of $n(t, r) / n_{0}$ were performed for $R=5 \mu \mathrm{m}, D=10^{-9} \mathrm{~m}^{2} / \mathrm{s}$ in the time interval $0<t<3 \mathrm{~ms}$. The legend shows the concentration, $n(t, r) / n_{0}$ which varies from 0 to 1 . The white arrows show the direction of the diffusion front propagation. Figure $(d)$ shows the total amount of diffusing substance entering or leaving the sphere as a function of time for $\beta=0,-0.5$ and 0.5 .

The total amount of diffusing substance entering or leaving the sphere is given in the form [36]

$$
\frac{M(t)}{M_{\infty}}=1-\frac{6}{\pi^{2}} \sum_{n=1}^{\infty} \frac{1}{n^{2}} \operatorname{Exp}\left[-\frac{D(1-\beta) \pi^{2} n^{2}}{R^{2}} t\right]
$$


where $M_{\infty}$ is the corresponding quantity after infinite time.

In Figure 2 (d), we plot the functions $M(t) / M_{\infty}$ for $\beta=0$ (no magnetic field), $\beta=0.5$ (paramagnetic species in a $M F$ ) and $\beta=-0.5$ (diamagnetic species in a MF). As seen in Figure $2(\mathrm{~d})$, the diffusion rate, $d M / d t$ (which is the curve slope) crucially depends on the magnetic field: for diamagnetic molecules in a MF $d M / d t$ increases, while for paramagnetic molecules this quantity decreases.

Thus, the magnetic field can significantly inhibit the diffusion of paramagnetic molecules (see Figure $2 b, d$ ), e.g., $\mathrm{O}_{2} ; \mathrm{FeCl}_{3}$; deoxyHb; intracellular and intercellular free radicals, such as $\mathrm{O}_{3}, \mathrm{NO}$, and $\mathrm{NO}_{2}$; and paramagnetic vesicles. On the contrary, a MF accelerates the diffusion of diamagnetic molecules (see Figure $2 c, d$ ). Below, we estimate the characteristic fields and values of the $\beta$-parameter (Eq. 6b) corresponding to the onset of the inhibition (or acceleration) of diffusion for paramagnetic and diamagnetic molecules.

We define the characteristic time scale of a diffusion process as $\tau_{0} \approx L^{2} / \mathrm{D}$, which appears in a solution of the equation for the diffusion in one dimension when $D$ is constant, $n(x) \sim t^{-1 / 2} \exp \left(-x^{2} / 4 D t\right)$. This solution describes the spreading by diffusion of a certain amount of substance deposited at time $t=0$ in the plane $x=0$. A characteristic time scale allows assessment of the key parameters influencing the diffusion process. In practice, a crude estimate of $\tau_{0}$ can be made knowing the diffusion coefficient and the lengthscale $(L)$ of a specific diffusion task. The characteristic time scale for diffusion in cells can be estimated from Eq. 7 as follows. The characteristic time for diffusion due to the concentration gradient is $\tau_{0} \approx \frac{L^{2}}{D}$. In a MF, for paramagnetic species, the characteristic diffusion time is

$$
\tau_{e f f} \approx \frac{L^{2}}{D_{e f f}}=\frac{\tau_{0}}{1-\beta}
$$

while for diamagnetic species this time is

$$
\tau_{e f f} \approx \frac{\tau_{0}}{(1+|\beta|)}
$$

In the limiting case $\beta \rightarrow 1$ (which corresponds to approaching the critical magnetic field $B_{c r}=\sqrt{\frac{2 \mu_{0} R T}{\chi}}$ ), the effective diffusion time of paramagnetic molecules goes to infinity, which implies that the magnetic field completely suppresses the concentration diffusion. For, $B>B_{\mathrm{cr}}$ the effective diffusion coefficient is negative, which means that paramagnetic species are squeezed by a strong enough magnetic field. Negative diffusion coefficients 
violate physical intuition because they indicate that species oppose their dilution. However, there are several ongoing discussions in the literature with regards to the existence of negative diffusion coefficients in [39-43] and references therein. These works give theoretical and experimental evidences supporting the existence of negative diffusion coefficients. In our case, it is possible to stop diffusion if the diffusion and magnetic fluxes are antiparallel and equal in magnitude, as these two fluxes will cancel each other out at the critical value of the magnetic induction, $B_{c r}$ (see Figure 1a for an illustration). Indeed, the diffusion and magnetic fluxes cancel each other out when the magnetic driving force (Eq.1) is equal to the diffusion driving force, $\overrightarrow{f_{D}}=R T \vec{\nabla} \mathrm{n}$ [25]: $\frac{\chi B^{2}}{2 \mu_{0}} \vec{\nabla} n=R T \vec{\nabla} \mathrm{n}$. It directly follows from this equation that $D_{e f f}=0$ at $\beta=1$ when approaching the critical magnetic field $B$ cr.

By setting the change of the characteristic diffusion time $\left(\tau_{\text {eff }}-\tau_{0}\right) / \tau_{0}=\beta /(1-\beta)= \pm 5 \%$, in Eqs. 11 , we define the parameter $\beta_{0} \approx 0.05$ as the value of the onset of a MF effect on diffusion.

Since diffusion processes determine the reference time scale for all other processes in cells as well as the propagation speed of signaling molecules during cell-to-cell communication [44], our results - the magnetic field dependences of the diffusion rate and characteristic time - may serve as an important key for revealing and understanding the mechanisms of magnetic field action on living cells, tissue and organisms.

\subsection{Diffusion of biologically active molecules in specific examples of biomedical applications}

In Table 1, for several biologically active molecules we present the MF induction values corresponding to $\beta_{0}=0.05$ at which a MF starts to affect diffusion as calculated from $B_{0}=\sqrt{\frac{2 \mu_{0} \beta_{0} R T}{\chi}}$. Below, we analyze the MF effects on diffusion of some biologically active molecules, such as oxygen and, reactive oxygen species (ROS), as well as molecules used as contrast agents in MRI and anticancer paramagnetic drugs. 
Table 1. Values of the magnetic field induction (in tesla), corresponding to the onsets of the MF effects on diffusion, as calculated from Eq. $6 \mathrm{~b}$ a for different paramagnetic and diamagnetic molecules and $\beta_{0}=0.05$. Gray colors indicate diamagnetic molecules.

\begin{tabular}{|c|c|c|}
\hline Molecules & $\chi, m^{3} / \mathrm{mol}, \quad$ Ref. & $\boldsymbol{B}_{\boldsymbol{0}}, \mathbf{T}$ \\
\hline deoxyHb & $+60.4 \cdot 10^{-8}$ & 22.8 \\
\hline metHb & $+7.217 \cdot 10^{-7}$ & 20.8 \\
\hline oxyHb & $-4.754 \cdot 10^{-7}$ & 25.7 \\
\hline $\mathrm{O}_{2}$ & $+4.3 \cdot 10^{-8}$ & 85.3 \\
\hline Gd & $+18.5 \cdot 10^{-8}$ & 41.2 \\
\hline $\mathrm{FeCl}_{3}$ & $+2.573 \cdot 10^{-8}$ & 110 \\
\hline $\mathrm{NO}$ & $+0.146 \cdot 10^{-8}$ & 463 \\
\hline $\mathrm{NO}_{2}$ & $+0.0150 \cdot 10^{-8} \quad[47]$ & 1445 \\
\hline $\mathrm{O}_{3}$ & $+0.00067 \cdot 10^{-8} \quad[47]$ & 6387 \\
\hline $\mathrm{CO}_{2}$ & $-0.0021 \cdot 10^{-8}$ & 3862 \\
\hline $\mathrm{O}_{2}^{-}$ & $-17.3 \cdot 10^{-12}$ & 4255 \\
\hline $\mathrm{MnCl}_{2}$ & $+3.8 \cdot 10^{-8}$ & 90.8 \\
\hline $\mathrm{Ho}\left(\mathrm{NO}_{3}\right)_{3}$ & $+11.34 \cdot 10^{-8}$ & 52.6 \\
\hline
\end{tabular}

\subsubsection{Diffusion of hemoglobin and oxygen in red blood cells}

The diffusion of hemoglobin and oxygen inside a red blood cell (RBC) drives the oxygen uptake and release by RBCs. Since deoxyhemoglobin (deoxyHb), methemoglobin (metHb) and oxygen $\left(\mathrm{O}_{2}\right)$ are paramagnetic species (see Table 1), the diffusion rates of $\mathrm{O}_{2}$, deoxyHb and metHb decrease in a MF, e.g. as shown in Figure 2(b). The diffusion coefficients of hemoglobin and oxygen at concentrations existing inside RBC are important parameters for quantitative description of oxygen uptake and release by RBCs. The mean diffusion time of Hb inside a RBC is of the order $\tau_{\mathrm{Hb}}=a^{2} / D_{H b} \approx 1 \mathrm{~s}$, where $D_{H b} \approx 1.6 \cdot 10^{-11} \mathrm{~m}^{2} / \mathrm{s}[50]$ or $D_{H b} \approx 3.4 \cdot 10^{-12} \mathrm{~m}^{2} / \mathrm{s}$ [51]. A large difference in the values of $D$ could be explained as follows. Cell is a living system, which is able to adapt its physical parameters to the alternating environment, e.g. by adjusting the diffusion coefficient, which in its turn can be modulated through conformational distributions in the protein. For instance, for LacI repressor proteins diffusing along with 
bioRxiv preprint doi: https://doi. org/10.1101/2020.10.08.331116; this version posted May 17, 2021. The copyright holder for this preprint (which was not certified by peer review) is the author/funder, who has granted bioRxiv a license to display the preprint in perpetuity. It is made available under aCC-BY-NC-ND 4.0 International license.

DNA, the measured 1D diffusion coefficients were found to vary in a large range, from $2.310^{-12} \mathrm{~cm}^{2} / \mathrm{s} \mathrm{to} 1.310^{-}$ ${ }^{9} \mathrm{~cm}^{2} / \mathrm{s}$ [52]. The oxygen diffusion time inside an RBC is of the order $\tau_{\mathrm{ox}}=a^{2} / D_{o x} \approx 10 \mathrm{~ms}$, where $a \approx 3 \mu \mathrm{m}$ is the $\mathrm{RBC}$ radius, and $\mathrm{D}_{\mathrm{ox}} \approx 10^{-9} \mathrm{~m}^{2} / \mathrm{s}$ is the $\mathrm{O}_{2}$ diffusivity inside $\mathrm{RBC}$ [38]. Thus, the characteristic time of oxygen diffusion is short compared with the time $\Delta t_{\text {trap }}$ associated with $\mathrm{O}_{2}$ trapping by $\mathrm{Hb}$, which is a few tens of milliseconds $[53,54]$. Thus, dynamics of oxygen capture by RBCs is characterized by the following time hierarchy: $\tau_{\mathrm{ox}}(\approx 10 \mathrm{~ms})<\Delta t_{\text {trap }}(\approx 10-100 \mathrm{~ms})<\tau_{\mathrm{Hb}}(\approx 1 \mathrm{~s})$. Of note here, Hb diffusion is the slowest process, and its characteristic time is comparable with the time that erythrocytes spend in the lung alveoli $\approx 800 \mathrm{~ms}[55$ 57]. Bearing in mind that the Hb diffusion time could be increased by a sufficiently high MF (see Table 1), one can conclude that a $20 \mathrm{~T}$ magnetic field application may decrease the blood saturation by oxygen if $\tau_{\mathrm{Hb}}$ becomes greater than $800 \mathrm{~ms}$. Of note, as above mentioned, $\sim 20 \mathrm{~T}$ MFs are currently used in ultrahigh resolution MRI scanners.

Diffusion is closely related to cell homeostasis. Indeed, when homeostasis is threatened in a cell, diffusion helps to maintain balance in cellular concentrations. Thus, a MF applied to a whole cell body can disturb its dynamic equilibrium (homeostasis) and change the both cell shape and its volume. The concentration-gradient magnetic force (Eq. 1) pushes $\mathrm{Hb}$-molecules towards the RBC membrane and creates a magnetic pressure on it. In fact, the RBC membrane is impermeable to hemoglobin. Knowing the volume density of the magnetic force (Eq. 2), one can calculate the magnetic pressure of $\mathrm{Hb}$ on the cell membrane as $\mathrm{P}=f \mathrm{~V} / S$, where $V$ is the cell volume and $S$ is the membrane area. For a spherical cell one can arrive at the following equation:

$$
P_{m a g}=\frac{\chi R_{C} B^{2} \nabla n}{6 \mu_{0}}
$$

where $R_{c}$ is the mean cell radius. For deoxyHb the magnetic susceptibility is $\chi_{\mathrm{Hb}}=60.4 \cdot 10^{-8}\left(\mathrm{~m}^{3} / \mathrm{mol}\right)$ [45]. Magnetic susceptibilities for $\mathrm{Hb}$ and metHb are $\chi_{\mathrm{Hb}}=-4.75410^{-7}\left(\mathrm{~m}^{3} / \mathrm{mol}\right)$ and $\chi_{\mathrm{metHb}}=7.21710^{-7}\left(\mathrm{~m}^{3} / \mathrm{mol}\right)[46]$, respectively. The other relevant parameters of $\mathrm{Hb}$ are: the molecular weight of deoxyHb is $\mathrm{M}_{\mathrm{Hb}}=64450 \mathrm{~g} / \mathrm{mol}$ [58], the molar volume of $\mathrm{Hb}$ in solution is $\mathrm{v}_{\mathrm{m}}=48277 \mathrm{~mL} / \mathrm{mol}[59]$ and $\mathrm{Hb}$ concentration is $\mathrm{n}_{\mathrm{Hb}}=5.5 \mathrm{~mol} / \mathrm{m}^{3}$ [60]. Eq. 12 describes the ability of the magnetic pressure to disturb the cell pressure balance and change the RBC volume. The RBC volume magnetic susceptibilities were determined by SQUID [61]: $\chi_{\mathrm{RBC}}=-9.23 \times 10^{-6}(\mathrm{oxy}$ $\mathrm{RBC}),-5.72 \times 10^{-6}$ (deoxy RBC), and $-5.27 \times 10^{-6}$ (met RBC), in the SI units system. 
Now, we estimate the magnetic pressure exerted on deoxyHb in RBCs. The above shown Hb susceptibility and intracellular concertation, $R_{c}=4 \mu \mathrm{m}$ and the volume averaged concentration gradient $\nabla \mathrm{n}=\mathrm{n}_{\mathrm{nb}} / \mathrm{R}_{\mathrm{c}}$ (a layer of absorbed deoxyHb is located on the inner surface of an erythrocyte as depicted in Figure 3), for a completely deoxygenated $\mathrm{RBC}$ in a static MF with $\mathrm{B}=100 \mathrm{~T}$ are inserted in Eq. 12. Thus, we obtain magnetic pressure $\mathrm{P}_{\mathrm{mag}} \approx 4000 \mathrm{~Pa}$. We suppose that a magnetic pressure of hundreds Pa magnitude can disturb the cell pressure balance determined by osmotic pressure, hydrostatic pressure and membrane and cortical tension [62]. For example, mitotic HeLa cells exert a rounding pressure (pressure generated by mitotic cells to create space to divide) of 10-150 Pa [63].

As noted in Eq. 12, the magnetic pressure is proportional to the square of magnetic induction and the concentration gradient of the deoxyHb. We conclude that in a sufficiently high magnetic field a completely deoxygenated red blood cell exhibits swelling due to magnetic pressure (Figure 3), while a completely oxygenated red blood cell does not change its volume. Thus, the swelling effect could be well pronounced only for completely deoxygenated erythrocytes. Despite this findings, the cell membrane integrity is preserved with a strain as high as $40-50 \%$ [64]. In sufficiently high magnetic fields ( $\sim 100 \mathrm{~T}$ ) magnetic pressure (Eq. 12) and swelling can cause RBC membrane rupture. 


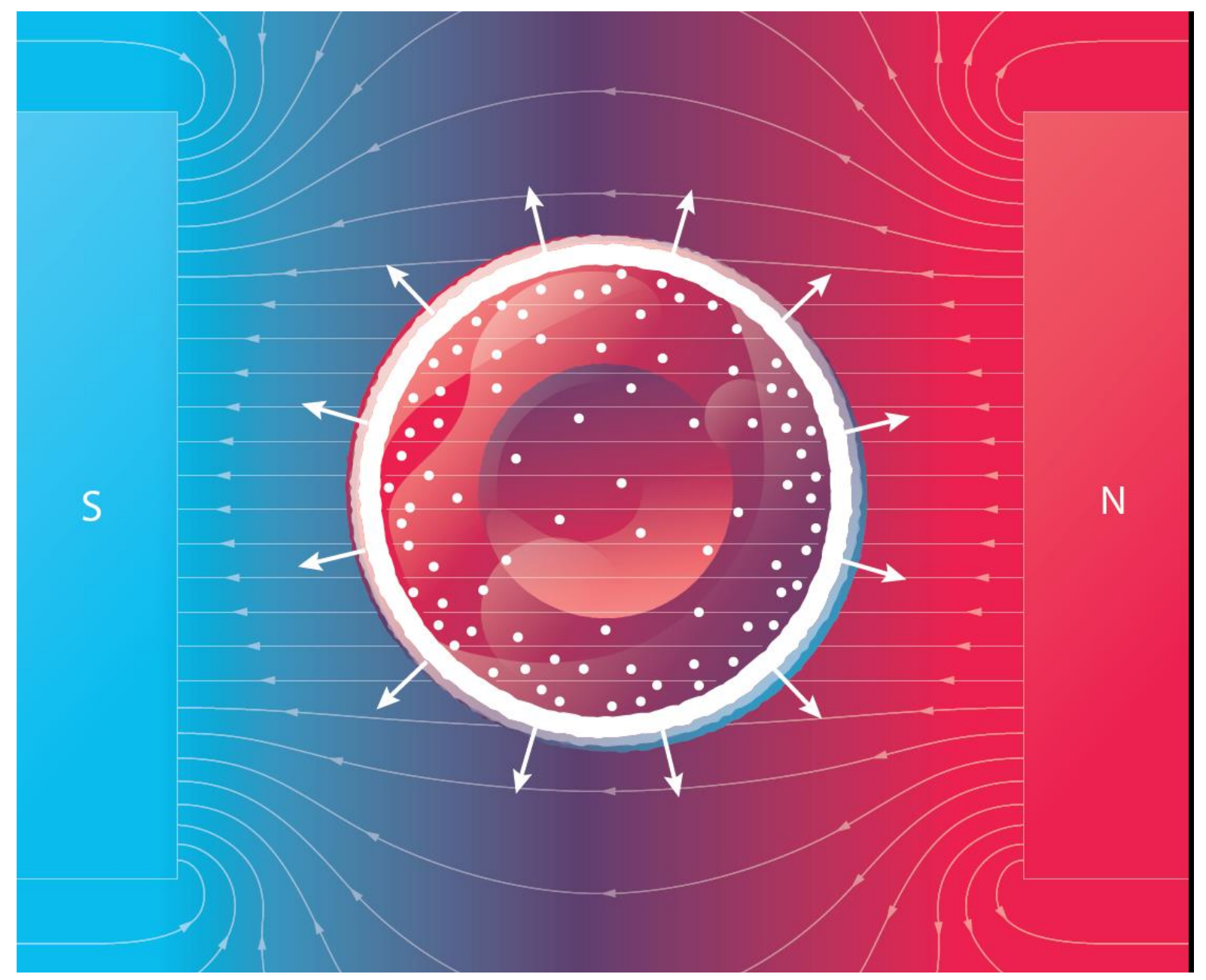

Figure 3. Scheme of a deoxygenated red blood cell under magnetic pressure on deoxyHb. The white radial arrows show directions of the magnetic concentration-gradient forces. Small white circles represent deoxyHb molecules, while the large white circle represents a layer of absorbed deoxyHb on the inner surface of the membrane of a RBC.

It should be noted here that regardless of the above described swelling mechanism, magnetically induced swelling and shape changing of cells (with no paramagnetic agents) have been observed under the following conditions: i) osteoblasts adhered to glass substrates in the presence of a 5 T- magnetic field [65] and ii) human THP-1 leukemia cells (volume increase up to $90 \%$ ) after 24 hours of exposure to a spatially modulated high-gradient magnetic field [66].

An interesting aspect of magnetically induced RBC swelling that deserves further study is the diffusion of oxygen $\left(\mathrm{O}_{2}\right)$ through the $\mathrm{RBC}$ membrane. Given that $\mathrm{O}_{2}$ is paramagnetic, the concentration-gradient magnetic force (Eq. 
bioRxiv preprint doi: https://doi. org/10.1101/2020.10.08.331116; this version posted May 17, 2021. The copyright holder for this preprint (which was not certified by peer review) is the author/funder, who has granted bioRxiv a license to display the preprint in perpetuity. It is made available under aCC-BY-NC-ND 4.0 International license.

1) pushes $\mathrm{O}_{2}$-molecules either outside or inside an $\mathrm{RBC}$ depending on the direction of the gradient $\nabla n_{\mathrm{O} 2}$, thereby facilitating/complicating oxygen transport in capillaries. Moreover, mitochondrial function in cells is also crucially dependent on the diffusion rate of $\mathrm{O}_{2}$-molecules, which could be decreased by a sufficiently high magnetic field (see Table 1).

\subsubsection{Diffusion of ROS}

Cytoplasmic and mitochondrial ROS play a dual (harmful and beneficial) role in the cell machinery and are important regulators of cellular life processes in health and disease [67]. The intracellular ROS level is dependent on the dynamic balance between ROS generation and elimination, and ROS diffuse between sources and sinks in cytoplasm. Importantly, in most cases, the application of a MF results in increased the ROS level in cells and tissues [32]. The possibility of MF effects on ROS diffusion relies on the fact that intracellular and intercellular free radicals, such as $\mathrm{O}_{3}, \mathrm{NO}$, and $\mathrm{NO}_{2}$, are paramagnetic (for their paramagnetic susceptibilities see Table 1) and can be redistributed by magnetic concentration-gradient forces (Eq. 3). The following question arises: does static uniform MF significantly contribute to the diffusion of the paramagnetic ROS? Here, we determine that the answer to this question is probably, no at least for MFs with magnitudes less than hundreds of tesla (see Table 1).

\subsubsection{Diffusion of molecules used in medicine and paramagnetic drugs}

The study of MF effects on diffusion of paramagnetic molecules used as contrast agents in MRI and paramagnetic drugs is especially important in the field of diagnostic and therapeutic. For example, $\mathrm{FeCl}_{3}$ - induced arterial thrombosis is used to control bleeding from damaged blood vessels. The experiments [68] showed that ferric chloride $\left(\mathrm{FeCl}_{3}\right)$ compared to the current standard method, which includes suturing the bleeding site, requires significantly less time to control bleeding with even the lowest concentration of ferric chloride. Ultrastructural analysis revealed that $\mathrm{FeCl}_{3}$ diffused through the vessel wall, resulting in endothelial cell denudation without exposure of the inner layers [69].

Let us analyze how diffusion of $\mathrm{FeCl}_{3}$ through the blood vessel wall can be affected by an MF. Ferric chloride is paramagnetic with a magnetic susceptibility $\chi=+1.345 \cdot 10^{-8} \mathrm{~m}^{3} / \mathrm{mol}$ (see Table 1). As described in Section 2.2 a sufficiently high MF will hinder and slow $\mathrm{FeCl}_{3}$ diffusion. Thus, magnetically hindered thrombosis with $\mathrm{FeCl}_{3}$ 
bioRxiv preprint doi: https://doi.org/10.1101/2020.10.08.331116; this version posted May 17, 2021. The copyright holder for this preprint (which was not certified by peer review) is the author/funder, who has granted bioRxiv a license to display the preprint in perpetuity. It is made available under aCC-BY-NC-ND 4.0 International license.

will require a greater concentration of $\mathrm{FeCl}_{3}$ compared with its application with no magnetic field. The effects of MF on the $\mathrm{FeCl}_{3}$-induced thrombosis were studied in rat model experiments [70]. In the group of rats exposed to a static $600-\mathrm{mT}$ magnetic field thrombus protein content $(0.28 \pm 0.14 \mathrm{mg} / \mathrm{ml})$ was downregulated compared with the model control group $(0.47 \pm 0.10 \mathrm{mg} / \mathrm{ml})$. This MF effect has been putatively explained by MF-induced vascular smooth muscle relaxation and blood viscosity reduction. In light of that mentioned above, it is unlikely that the observed decrease in thrombus protein content in $600 \mathrm{mT}$ - MF could be caused by impaired diffusion of $\mathrm{FeCl}_{3}$ to the bleeding site. Indeed, as noted in Table 1, MFs with induction greater than one hundred teslas affect $\mathrm{FeCl}_{3}$ diffusion.

The paramagnetic ion gadolinium Gd(III) is used commonly in MRI contrast agents to provide increased contrast $[2,71]$. Importantly, this agent is paramagnetic with a sufficiently high magnetic susceptibility, $\chi=18.5 \cdot 10^{-8}$ $\mathrm{m}^{3} / \mathrm{mol}$, see Table 1 . Thus, for MFs with induction $B<40 \mathrm{~T}$, the MF effect on Gd diffusion is expected to be negligible. Thus, no inexpedient diffusional effects on the required distribution of Gd contrast agent are observed from a MF in an MRI machine.

Two paramagnetic species with the highest magnetic susceptibility values are found in the last two rows of Table 1: $\mathrm{MnCl}_{2}$ and $\mathrm{Ho}\left(\mathrm{NO}_{3}\right)_{3}$. Manganese chloride is used as a nutraceutical and an MRI contrast agent. Holmium $\left(\mathrm{Ho}^{166}\right)$ and holmium nitrate are used in medicine for various therapeutic applications, including intratumoural cancer treatment, targeted therapies, skin patches, bone-seeking agents in bone marrow transplantation, and selective internal radiation therapy (SIRT) [72]. After injection of drug into a specific site or organ, the drug concentration decreases due to diffusion and biodistribution. Thus, the drug efficacy decreases with time. Therefore, the following important question arises: Is it possible to prevent drug diffusion from the target with a MF. The answer is probably yes. However, this requires applications of MFs with an induction of 50-100 T (see Table 1). Importantly, such a high MF would prevent common drug side effects related to undesirable drug biodistribution outside the target site. Of note, as mentioned in the introduction, currently, static 40-50 T-magnetic fields are reachable in the lab, while MFs of thousand teslas are only attainable using a pulsed regime.

\section{Conclusions and Prospects}

We have analyzed the roles of static MFs and the magnetic concentration-gradient forces in diffusion of paramagnetic and diamagnetic molecules. It was shown that a high magnetic field accelerates the diffusion of diamagnetic molecules and reduces the diffusion of paramagnetic molecules. We have revealed the underlying 
bioRxiv preprint doi: https://doi.org/10.1101/2020.10.08.331116; this version posted May 17, 2021. The copyright holder for this preprint (which was not certified by peer review) is the author/funder, who has granted bioRxiv a license to display the preprint in perpetuity. It is made available under aCC-BY-NC-ND 4.0 International license.

mechanisms of magnetically affected diffusion and the key parameter that determines the strength of the MF effect on diffusion, namely, the ratio between the magnetic field energy and that of thermal fluctuations (see Eq. 6b). As above mentioned, at low temperatures, one can expect a sufficient acceleration of the diffusion of diamagnetic molecules by a MF. This effect might be important for cryobiology, in particular, for magnetic cryoconservation of cells and tissues. Indeed, numerous experimental studies have demonstrated the enhanced cells and organisms survival after freezing in presence of magnetic fields. For example, in 0.2-0.4 $\mathrm{T}$ static magnetic field, human erythrocytes were frozen to the temperature of $-20^{\circ} \mathrm{C}$ [73] . Rat mesenchymal stem cells were slowly frozen and cryopreserved for 7 days at $-150{ }^{\circ} \mathrm{C}$ [74]. In spite of physical and biological mechanisms of magnetofreezing still being poorly understood, it is obvious that since the diffusion serves as the reference time scale for all other processes in cells, the diffusion of biologically active molecules plays a key role in the survival of cells during freezing and thawing.

Magnetic field effects are also expected in reaction-diffusion systems with paramagnetic solutes. Although there is a curious and incompletely understood way in which these reactions seem to be magnetic field - dependent, direct effects of the magnetic concentration-gradient forces exerted on diffusing molecules may result in novel reaction pathways and MF-driven pattern formation.

We have theoretically predicted a new biological effect of homogeneous high magnetic fields: magnetically induced swelling of deoxygenated red blood cells. A deoxygenated erythrocyte contains deoxygenated hemoglobin, which is paramagnetic. In a high magnetic field, due to the large radial gradient of deoxyHb, the magnetic pressure (Eq. 12) exerted on deoxyHb causes erythrocytes swelling as depicted in Figure 3. As the erythrocyte volume increases, the surface of its membrane also increases. The increase of the membrane area subsequently leads to an increase in the amount of oxygen molecules diffusing into the erythrocyte. Through a chain of chemical reactions, these oxygen molecules bind to $\mathrm{Hb}$ making it diamagnetic. Then the magnetic pressure falls to zero, and the initial volume is restored in the erythrocyte. RBC swelling and shape alternations in MFs could affect (probably hinder) oxygen transport from capillaries to tissue. Experimental verification of the prediction of magnetically induced RBC swelling could answer the following important question: how does high magnetic field (e.g., in ultrahigh resolution MRI scanners) affect human health?

Our study has gleaned new insights into the potential biomedical applications of high and ultrahigh magnetic fields and provided new perspectives on the control of diffusion in cells and tissues. In terms of future directions for the development of magnetotherapy [75], our findings argue that cell-to-cell communication can also be 
bioRxiv preprint doi: https://doi. org/10.1101/2020.10.08.331116; this version posted May 17, 2021. The copyright holder for this preprint (which was not certified by peer review) is the author/funder, who has granted bioRxiv a license to display the preprint in perpetuity. It is made available under aCC-BY-NC-ND 4.0 International license.

directly affected by MFs. Indeed, the propagation time of chemical signals across the cell envelope, extracellular matrix and tissue is limited by diffusion. Therefore, changes in characteristic diffusion time and subsequent cell signaling alterations induced by a MF represent an intriguing perspective to improve the understanding molecular signaling pathways and develop new treatment approaches for cell therapy. Thus, the application of the elaborated diffusion model and MFs is of vital importance for future studies of cell signaling processes, cell therapy, disease modeling, tissue regeneration, magnetic surgery [76] and tissue engineering using magnetic fields [77].

\section{Figures Captions}

Figure 1. Sketch of magnetically affected diffusion of paramagnetic $(a)$ and diamagnetic molecules $(b)$. The yellow arrows represent the magnetic field lines. The large blue arrow shows the concentration gradient $\nabla \mathrm{n}$ of solute. Red arrows show magnetic concentration-gradient forces (Eq. 3) acting on molecules.

Figure 2. MF effect on diffusion in a sphere: the contour plots of $n(t, r) / n_{0}$ given by Eq. 9 . The sphere is initially at a uniform zero concentration and the surface concentration is maintained constant at $n_{o}$. The curves represent $\left.n(t, r) / n_{0}: a\right)$ with no magnetic field $\left.(\beta=0), b\right)$ with a magnetic field corresponding $\beta=0.5$ (paramagnetic species) and $c$ ) with a magnetic field corresponding $\beta=-0.5$ (diamagnetic species). The calculations of $n(t, r) / n_{0}$ were performed for $R=5 \mu \mathrm{m}, D=10^{-9} \mathrm{~m}^{2} / \mathrm{s}$ in the time interval $0<t<3 \mathrm{~ms}$. The legend shows the concentration, $n(t, r) / n_{0}$ which varies from 0 to 1 . The white arrows show the direction of the diffusion front propagation. Figure $(d)$ shows the total amount of diffusing substance entering or leaving the sphere as a function of time for $\beta=0,-0.5$ and 0.5 .

Figure 3. Scheme of a deoxygenated red blood cell under magnetic pressure on deoxyHb. The white radial arrows show directions of the magnetic concentration-gradient forces. Small white circles represent deoxyHb molecules, while the large white circle represents a layer of absorbed deoxyHb on the inner surface of the membrane of a RBC.

Funding This project is partially supported by Operational Programme Research, Development and Education, financed by the European Structural and Investment Funds and the Czech Ministry of Education, Youth and Sports through Project No. SOLID21 - CZ.02.1.01/0.0/0.0/16_019/0000760). 
Author Contributions:

V. Z., T. P., and A. D. contributed equally to this work. All authors read and approved the final manuscript.

Conflict of interest The authors declare that they have no conflicts of interest with the contents of this article.

\section{References}

1 Sharma S, Sharma R. 2009. 21 Tesla MRI Microscopy of Mice Kidney, Heart and Skin: Quantitation of MRI Visible Features. Nature Precedings.

2 Magdoom KN, Brown A, Rey J, Mareci TH, et al. 2019. MRI of Whole Rat Brain Perivascular Network Reveals Role for Ventricles in Brain Waste Clearance. Sci Rep-Uk 9: 11480.

3 Nakamura D, Ikeda A, Sawabe H, Matsuda YH, et al. 2018. Record indoor magnetic field of 1200 T generated by electromagnetic flux-compression. Review of Scientific Instruments 89 : 095106.

4 Law KFF, Bailly-Grandvaux M, Morace A, Sakata S, et al. 2016. Direct measurement of kilotesla level magnetic field generated with laser-driven capacitor-coil target by proton deflectometry. Appl Phys Lett 108: 091104.

$5 \quad$ Fujioka S, Zhang Z, Ishihara K, Shigemori K, et al. 2013. Kilotesla Magnetic Field due to a Capacitor-Coil Target Driven by High Power Laser. Sci Rep-Uk 3: 1170.

6 Waskaas M. 1993. Short-term effects of magnetic fields on diffusion in stirred and unstirred paramagnetic solutions. The Journal of Physical Chemistry 97: 6470-6.

$7 \quad$ Kinouchi Y, Tanimoto S, Ushita T, Sato K, et al. 1988. Effects of static magnetic fields on diffusion in solutions. Bioelectromagnetics 9: 159-66.

8 Zhang X, Yarema K, Xu A. 2017. Impact of Static Magnetic Fields (SMFs) on Cells. Biological Effects of Static Magnetic Fields. Singapore: Springer Singapore. p 81-131.

9 Miyakoshi J. 2005. Effects of static magnetic fields at the cellular level. Prog Biophys Mol Bio 87: 213-23.

10 Hirose H, Nakahara T, Zhang Q-M, Yonei S, et al. 2003. Static magnetic field with a strong magnetic field gradient $(47.7 \mathrm{~T} / \mathrm{m})$ induces C-Jun expression in HL-60 cells. In Vitro Cellular \& Developmental Biology - Animal 39: 348-52.

11 Tian XF, Wang DM, Feng S, Zhang L, et al. 2019. Effects of 3.5-23.0 T static magnetic fields on mice: A safety study. Neuroimage 199: 273-80.

12 Oliveira FTP, Diedrichsen J, Verstynen T, Duque J, et al. 2010. Transcranial magnetic stimulation of posterior parietal cortex affects decisions of hand choice. Proceedings of the National Academy of Sciences 107: 17751-6.

13 Zablotskii V, Lunov O, Novotna B, Churpita O, et al. 2014. Down-regulation of adipogenesis of mesenchymal stem cells by oscillating high-gradient magnetic fields and mechanical vibration. Appl Phys Lett 105: 103702.

14 Wosik J, Chen W, Qin K, Ghobrial RM, et al. 2018. Magnetic Field Changes Macrophage Phenotype. Biophys J 114: 2001-13.

15 Yang X, Song C, Zhang L, Wang J, et al. 2021. An upward 9.4 T static magnetic field inhibits DNA synthesis and increases ROS-P53 to suppress lung cancer growth. Translational Oncology 14: 101103.

16 Dini L, Abbro L. 2005. Bioeffects of moderate-intensity static magnetic fields on cell cultures. Micron 36: 195-217. 
17 Yang X, Li, Z., Polyakova, T., Dejneka, A., Zablotskii, V. and Zhang, X. 2020. Effect of Static Magnetic Field on DNA Synthesis: The Interplay between DNA Chirality and Magnetic Field Left-Right Asymmetry. FASEB BioAdvances 2: 254-63.

18 Rubio Ayala M, Syrovets T, Hafner S, Zablotskii V, et al. 2018. Spatiotemporal magnetic fields enhance cytosolic $\mathrm{Ca2}+$ levels and induce actin polymerization via activation of voltage-gated sodium channels in skeletal muscle cells. Biomaterials 163: 174-84.

19 Wang CX, Hilburn IA, Wu D-A, Mizuhara Y, et al. 2019. Transduction of the Geomagnetic Field as Evidenced from Alpha-band Activity in the Human Brain. eneuro: ENEURO.048318.2019.

20 Barbic M. 2019. Possible magneto-mechanical and magneto-thermal mechanisms of ion channel activation in magnetogenetics. Elife 8: e45807.

21 Lei H, Pan Y, Wu R, Lv Y. 2020. Innate Immune Regulation Under Magnetic Fields With Possible Mechanisms and Therapeutic Applications. Frontiers in Immunology 11.

22 Grant A, Metzger GJ, Van de Moortele P-F, Adriany G, et al. 2020. 10.5 T MRI static field effects on human cognitive, vestibular, and physiological function. Magnetic Resonance Imaging 73: 163-76.

23 Tkáč I, Benneyworth MA, Nichols-Meade T, Steuer EL, et al. Long-term behavioral effects observed in mice chronically exposed to static ultra-high magnetic fields. Magnet Reson Med n/a.

24 Zhang L, Hou Y, Li Z, Ji X, et al. 2017. 27 T ultra-high static magnetic field changes orientation and morphology of mitotic spindles in human cells. eLife 6: e22911.

25 Hinds G, Coey JMD, Lyons MEG. 2001. Influence of magnetic forces on electrochemical mass transport. Electrochem Commun 3: 215-8.

26 Zablotskii V, Lunov O, Kubinova S, Polyakova T, et al. 2016. Effects of high-gradient magnetic fields on living cell machinery. Journal of Physics D: Applied Physics 49: 493003.

27 Zablotskii V, Polyakova T, Dejneka A. 2018. Cells in the Non-Uniform Magnetic World: How Cells Respond to High-Gradient Magnetic Fields. BioEssays 40: 1800017.

28 Dunne P, Mazza L, Coey JMD. 2011. Magnetic Structuring of Electrodeposits. Phys Rev Lett 107: 024501.

29 Leventis N, Dass A. 2005. Demonstration of the elusive concentration-gradient paramagnetic force. Journal of the American Chemical Society 127: 4988-9.

30 Zablotskii V, Polyakova T, Dejneka A. 2021. Modulation of the Cell Membrane Potential and Intracellular Protein Transport by High Magnetic Fields. Bioelectromagnetics 42: 27-36.

31 Sear RP. 2019. Diffusiophoresis in Cells: A General Nonequilibrium, Nonmotor Mechanism for the Metabolism-Dependent Transport of Particles in Cells. Phys Rev Lett 122: 128101.

Wang H, Zhang X. 2017. Magnetic Fields and Reactive Oxygen Species. Int J Mol Sci 18: 2175. Tikhonov AN. 1963. Equations of Mathematical Physics Oxford-London-NY-Paris: Pergamon Press.

34 Lifshitz EM, Pitaevskii LP. 1995. Physical Kinetics: Volume 10: Elsevier Science.

35 Hardt S, Hartmann J, Zhao SC, Bandopadhyay A. 2020. Electric-Field-Induced Pattern Formation in Layers of DNA Molecules at the Interface between Two Immiscible Liquids. Phys Rev Lett 124: 064501.

36 J C. 1975. The Mathematics of Diffusion: Oxford University Press.

37 Wolfram Research I. 2020. Mathematica. Champaign, Illinois: Wolfram Research, Inc.

38 Kang M-Y, Katz I, Sapoval B. 2015. A new approach to the dynamics of oxygen capture by the human lung. Respiratory Physiology \& Neurobiology 205: 109-19.

39 Miller DG. 1986. Some comments on multicomponent diffusion: negative main term diffusion coefficients, second law constraints, solvent choices, and reference frame transformations. The Journal of Physical Chemistry 90: 1509-19.

40 Clark WM, Rowley RL. 1985. Ternary liquid diffusion coefficients near plait points. International Journal of Thermophysics 6: 631-42. 
41 Buzatu D, Buzatu FD, Paduano L, Sartorio R. 2007. Diffusion Coefficients for the Ternary System Water + Chloroform + Acetic Acid at $25^{\circ} \mathrm{C}$. Journal of Solution Chemistry 36: 1373-84. Vitagliano V, Sartorio R, Scala S, Spaduzzi D. 1978. Diffusion in a ternary system and the critical mixing point. Journal of Solution Chemistry 7: 605-22.

Kozlova S, Mialdun A, Ryzhkov I, Janzen T, et al. 2019. Do ternary liquid mixtures exhibit negative main Fick diffusion coefficients? Physical Chemistry Chemical Physics 21: 2140-52. Reguera G. 2011. When microbial conversations get physical. Trends in Microbiology 19: 105-13.

Spees WM, Yablonskiy DA, Oswood MC, Ackerman JJH. 2001. Water proton MR properties of human blood at 1.5 Tesla: Magnetic susceptibility, T-1, T-2, T-2* and non-Lorentzian signal behavior. Magnet Reson Med 45: 533-42. release from red blood cells as a function of age based on magnetic susceptibility measurements. Analyst 136: 2996-3003.

Smits vCJGuL. 1957. Relaxation Paramagnétique. Paris: Verlag Masson. Rosensweig RE. 2014. Ferrohydrodynamics: Dover Publications.

51 L.R. Adams IF. 1967. The diffusion coefficient of human hemoglobin at high concentrations. Respiration Physiology 2: 293-301.

52 Wang YM, Austin RH, Cox EC. 2006. Single Molecule Measurements of Repressor Protein 1D Diffusion on DNA. Phys Rev Lett 97: 048302.

53 Hook C, Yamaguchi K, Scheid P, Piiper J. 1988. Oxygen-Transfer of Red Blood-Cells Experimental-Data and Model Analysis. Respiration Physiology 72: 65-82.

Piiper J, Hook C, Yamaguchi K, Scheid P. 1988. Modeling of Oxygen-Transfer Kinetics of Red Blood-Cells. Faseb J 2: A925-A.

Di Caprio G, Stokes C, Higgins JM, Schonbrun E. 2015. Single-cell measurement of red blood cell oxygen affinity. Proceedings of the National Academy of Sciences of the United States of America 112: 9984-9.

56 DR Peterson JB. 2014. Biomechanics: principles and practices.

57 Yamaguchi K, Nguyen-Phu D, Scheid P, Piiper J. 1985. Kinetics of O2 uptake and release by human erythrocytes studied by a stopped-flow technique. J Appl Physio/ 58: 1215-24.

58 Dickerson RE, Geis I. 1983. Hemoglobin : structure, function, evolution, and pathology Menlo Park, Calif.: Benjamin/Cummings Pub. Co.

59 Cerdonio M, Congiu-Castellano A, Calabrese L, Morante S, et al. 1978. Room-temperature magnetic properties of oxy- and carbonmonoxyhemoglobin. Proceedings of the National Academy of Sciences 75: 4916-9.

60 Hillman R FC. 1996. The red cell manual. Philadelphia: FA Davis, Co.

61 Xue W, Moore LR, Nakano N, Chalmers JJ, et al. 2019. Single cell magnetometry by magnetophoresis vs. bulk cell suspension magnetometry by SQUID-MPMS - A comparison. $J$ Magn Magn Mater 474: 152-60.

62 Jiang H, Sun Sean X. 2013. Cellular Pressure and Volume Regulation and Implications for Cell Mechanics. Biophys J 105: 609-19.

63 Stewart MP, Helenius J, Toyoda Y, Ramanathan SP, et al. 2011. Hydrostatic pressure and the actomyosin cortex drive mitotic cell rounding. Nature 469: 226-30.

64 Li FF, Chan CU, OhI CD. 2013. Yield Strength of Human Erythrocyte Membranes to Impulsive Stretching. Biophys J 105: 872-9.

65 Iwasaka M. 2019. Deformation of cellular components of bone forming cells when exposed to a magnetic field. AIP Advances 9: 035327. 
bioRxiv preprint doi: https://doi org/10.1101/2020.10.08.331116 - this version posted May 17, 2021. The copyright holder for this preprint (which was not certified by peer review) is the author/funder, who has granted bioRxiv a license to display the preprint in perpetuity. It is made available under aCC-BY-NC-ND 4.0 International license.

66 Zablotskii V, Syrovets T, Schmidt ZW, Dejneka A, et al. 2014. Modulation of monocytic leukemia cell function and survival by high gradient magnetic fields and mathematical modeling studies. Biomaterials 35: 3164-71.

67 Di Meo S, Reed TT, Venditti P, Victor VM. 2016. Role of ROS and RNS Sources in Physiological and Pathological Conditions. Oxid Med Cell Longev 2016.

68 Nouri S, Sharif MR, Sahba S. 2015. The Effect of Ferric Chloride on Superficial Bleeding. Trauma Mon 20.

69 ECKLY A, HECHLER B, FREUND M, ZERR M, et al. 2011. Mechanisms underlying FeCl3induced arterial thrombosis. Journal of Thrombosis and Haemostasis 9: 779-89.

70 Li Q, Liao Z, Gu L, Zhang L, et al. 2020. Moderate Intensity Static Magnetic Fields Prevent Thrombus Formation in Rats and Mice. Bioelectromagnetics 41: 52-62.

71 Merbach AE, Toth, E. 2001. The Chemistry of Contrast iAgents in Medical Magnetic Resonance Imaging New York: John Wiley \& Sons, Ltd.

72 Klaassen NJM, Arntz MJ, Gil Arranja A, Roosen J, et al. 2019. The various therapeutic applications of the medical isotope holmium-166: a narrative review. EJNMMI Radiopharmacy and Chemistry 4: 19.

73 Lin C-Y, Chang W-J, Lee S-Y, Feng S-W, et al. 2013. Influence of a static magnetic field on the slow freezing of human erythrocytes. Int J Radiat Biol 89: 51-6.

74 Shikata H, Kaku M, Kojima SI, Sumi H, et al. 2016. The effect of magnetic field during freezing and thawing of rat bone marrow-derived mesenchymal stem cells. Cryobiology 73: 15-9.

75 Pesqueira T, Costa-Almeida R, Gomes ME. 2018. Magnetotherapy: The quest for tendon regeneration. Journal of Cellular Physiology 233: 6395-405.

76 Lv Y, Shi Y, First International Conference of Magnetic Surgery SCot. 2019. Xi'an consensus on magnetic surgery. Hepatobiliary Surgery and Nutrition 8: 177-8.

77 Parfenov VA, Khesuani YD, Petrov SV, Karalkin PA, et al. 2020. Magnetic levitational bioassembly of 3D tissue construct in space. Science Advances 6: eaba4174. 